\title{
A Comparative Study of Outcome of Post-Operative Mastoid Cavity Obliteration with Autologous Cartilage with That of Unobliterated Cavities
}

\author{
Amit Bikram Maiti1 ${ }^{1}$ Rupam Sinha ${ }^{2}$ \\ 1Department of ENT, Purulia Government Medical College and Hospital, Purulia, West Bengal, India. \\ ${ }^{2}$ Department of ENT, Khatra Sub-Division Hospital, Bankura, West Bengal, India.
}

\section{ABSTRACT}

\section{BACKGROUND}

Mastoid operations have been in practice for over four centuries for suppurative conditions of the ear. Intact canal wall mastoidectomy has the advantage of rapid wound healing and also avoids frequent cleaning of the cavity. With canal wall down mastoidectomy there is excellent exposure for disease eradication and postoperative monitoring but is associated with significant cavity problems. In order to overcome the problems associated with canal wall down procedure while retaining its advantages, the concept of mastoid cavity obliteration was introduced. We wanted to study the outcomes of mastoid cavity obliteration and compare the outcomes of mastoid cavity obliteration with autologous cartilage as obliterating material for mastoid obliteration.

\section{METHODS}

A prospective, experimental, randomized study has been conducted over a period of 18 months among patients presenting with active squamosal variety of Chronic Otitis Media wherein 15 cases were allotted to each group which subsequently underwent canal wall down mastoidectomy followed by obliteration with autologous cartilage.

\section{RESULTS}

The mean age of the individuals in group $\mathrm{A}$ is 25.47 years with a standard deviation of 8.89 years; in group B (obliteration with cartilage) it is 26.33 years with a standard deviation of 11.73 years. In group $A$, the mean duration required for complete epithelialization is 10.8 weeks while in group B, the average time taken for complete epithelialization is 5.07 weeks. All cases had their graft intact at the end of 12 weeks. Debris was present in group A for a mean duration of 9.47 weeks whereas in group B it is seen for a mean duration of 2.8 weeks. Patients from group A complained of discharge from their ears for a mean duration of 7.47 weeks. In group B the same symptom persisted over 2.8 weeks.

\section{CONCLUSIONS}

Cavity problems encountered are considerably less in the group obliterated with cartilage.

\section{KEY WORDS}

Mastoidectomy, Cartilage, Otorrhoea
Corresponding Author:

Dr. Rupam Sinha,

11/33, Sepco Township,

B-Zone, Durgapur-713205,

West Bengal, India.

E-mail: rupamsinhaad2@gmail.com

DOI: $10.14260 / j e m d s / 2020 / 437$

How to Cite This Article:

Maiti AB, Sinha R. A comparative study of outcome of post-operative mastoid cavity obliteration with autologous cartilage with that of unobliterated cavities. $J$. Evolution Med. Dent. Sci. 2020;9(28): 2007-2011, DOI

10.14260/jemds/2020/437

Submission 03-03-2020,

Peer Review 29-05-2020,

Acceptance 05-06-2020,

Published 13-07-2020.

Copyright (c) 2020 JEMDS. This is an open access article distributed under Creative Commons Attribution License [Attribution 4.0 International (CC BY 4.0)] 


\section{BACKGROUND}

Chronic otitis media is an inflammatory process in the middle-ear space that results in long-term, or more often, permanent changes in the tympanic membrane including atelectasis, dimer formation, perforation, tympanosclerosis, retraction pocket development or cholesteatoma. Nadol classified chronic otitis media as chronic active otitis media with or without cholesteatoma; chronic inactive otitis media with perforation, with retraction pocket, adhesive otitis media, with ossicular fixation or resorption; chronic inactive otitis media with frequent reactivation. ${ }^{1,2}$ Another proposed classification is based on classifying the disease into mucosal (active/inactive); squamosal (active/inactive) and healed. ${ }^{3}$

Mastoid operations have been in practice for over four centuries for suppurative conditions of the ear. Jansen described canal wall up mastoidectomy in 1953. The main advantage of canal wall up mastoidectomy is that normal anatomy can be preserved along with clearance of disease process. ${ }^{4}$ But in cases of unresectable cholesteatomas extending into petrous apex, unreconstructable posterior canal wall, failure of first stage canal wall up procedures because of poor Eustachian tube function, a canal wall down mastoidectomy is done which requires the removal of posterior wall of external auditory canal. ${ }^{5}$

Intact canal wall mastoidectomy has the advantage of rapid wound healing and also avoids frequent cleaning of the cavity. But the chances of residual disease as well as recurrent cholesteatoma is high with this procedure. ${ }^{6}$

With canal wall down mastoidectomy there is excellent exposure for disease eradication and post-operative monitoring; also there is less chance of leaving behind residual disease with low rates of recurrence. ${ }^{7}$ But it is associated with patient's intolerance to water exposure; frequent requirement of cleaning of cavity; calorically and barometrically induced vertigo; aesthetic inconvenience due to too large meatoplasty; recurrent infection; difficulty in wearing traditional hearing aids and also the final hearing gained after staged ossiculoplasties in patients who have undergone canal wall down mastoidectomy is usually 5-10 $\mathrm{dB}$ worse than those who underwent canal wall up tympanomastoidectomy due to ineffective sound transmission. $6,7,8.9$

In order to overcome the problems associated with canal wall down procedure while retaining its advantages the concept of mastoid cavity obliteration was introduced by Mosherin 19116. Over the course of this century, there have been numerous reports detailing a variety of techniques of obliterating the mastoid cavity. In developing countries like India where proper health care services is still not available to a sizeable chunk of the society, mastoid obliteration reduces the number of hospital visits one has to pay for cavity management.

\section{METHODS}

A prospective, experimental, randomized study was conducted over a period of 18 months amongst the patients attending the outpatients wing of department of Otorhinolaryngology of a peripheral referral institute from January 2017 to June 2018. All cases of chronic otitis media with cholesteatoma, with extensive granulations, with attic or postero-superior retraction pockets where the fundus is not visible were included in the study. Known cases of chronic otitis media with complications and those who didn't wish to participate in the study were excluded. The aims and

\section{Objectives}

1. To study the outcomes of mastoid cavity obliteration.

2. To compare the outcomes of mastoid cavity obliteration with cartilage as the obliterating material for mastoid obliteration with cases without obliteration (as control).

After proper selection, the patients were counselled about the disease process and the treatment modalities with the expected outcome and the complications of the procedures. They were then subjected to pure tone audiometry, X-ray mastoids, Examination under microscope, routine preoperative investigations followed by pre anaesthetic checkup. The patients were then divided into two groups by cluster sampling as follows-

Group-A: Canal Wall down (CWD) Mastoidectomy without obliteration.

Group-B: CWD Mastoidectomy with obliteration with cartilage.

Operative procedure: After induction of general anaesthesia, the ear is prepped and draped. Lignocaine (2\%) with 1:100000 adrenaline is infiltrated for haemostasis. Temporalis fascia graft is harvested. Post auricular incision is given. A Canal Wall Down mastoidectomy is done to remove any disease process in the mastoid \& middle ear. It is followed by ossicular reconstruction if required, followed by tympanoplasty. Then according to pre-determined protocol, the mastoid cavity may be left as such or obliterated using autologous cartilage. Post-operative treatment and follow ups- Each patient has been given an antibiotic, analgesic and antihistaminic medication for one week. Ear pack is removed two weeks after surgery. Patients were discharged on the second postoperative day. Patients were then appointed for follow-ups two weeks after pack removal, one and half month post-operative, 3 months postoperative for assessment of hearing by pure tone audiogram.

\section{Statistical Analyses}

After collection of data, all the data are entered into Microsoft office excel software and have been analyzed using appropriate statistical tests namely mean, standard deviation, paired and unpaired t tests.

\section{RESULTS}

The impacts of the surgical procedures undertaken were assessed on the based-on healing of mastoid cavity in terms of epithelialization, post-operative problems and hearing gain. 
Each group comprised of 15 individuals. The individuals have been divided into 4 age groups-5-15 years, 16-25 years, 26-35 years and 36-45 years. A total of 9 males and 6 females were in group A, 9 males and 6 females in group B. The mean age of the individuals in group $A$ is 25.47 years with a standard deviation of 8.89 years; in group B is 26.33 years with a standard deviation of 11.73 years. (Table 1)

\begin{tabular}{|c|c|c|c|c|}
\hline \multirow[t]{2}{*}{ Age Distribution } & \multicolumn{2}{|c|}{$\begin{array}{l}\text { CWD without } \\
\text { Obliteration } \\
\text { (as Control). }\end{array}$} & \multicolumn{2}{|c|}{$\begin{array}{c}\text { CWD with } \\
\text { Obliteration with } \\
\text { Cartilage }\end{array}$} \\
\hline & Males & Females & Males & Females \\
\hline 5-15 yrs. & 1 & 1 & 2 & 1 \\
\hline $16-25$ yrs. & 5 & 2 & 3 & 2 \\
\hline $26-35$ yrs. & 2 & 2 & 1 & 3 \\
\hline $36-45$ yrs. & 1 & 1 & 3 & 0 \\
\hline Total & 9 & 6 & 9 & 6 \\
\hline
\end{tabular}

The individuals in each group underwent Examination under microscope (EUM) prior to surgery. Individuals with attic pathology comprised the majority ( 5 cases in each group) followed by postero-superior retraction pockets (PSRP) and adhesive otitis media.

Conductive type of deafness was prevalent in both the groups with mixed deafness seen in only 2 cases in group A and 1 in group $B$. The pre-operative mean pure tone average in group $A$ is $47.6 \mathrm{~dB}$ with a standard deviation of $10.34 \mathrm{db}$. The mean Air-bone gap (A-B gap) in group A is $25.87 \mathrm{~dB}$ with a standard deviation of $9.99 \mathrm{db}$. In group $B$ the mean pure tone average is $41.8 \mathrm{~dB}$ with a standard deviation of $8.58 \mathrm{db}$. The mean A-B gap in group B is $21.8 \mathrm{~dB}$ with a standard deviation of $8.57 \mathrm{db}$. In groups $A$ and $B$ individuals mostly had moderate degree of hearing loss followed closely by individuals with mild degree of loss ( 9 moderate and 4 mild in group A; 10 moderate and 3 mild in group B).

On classifying the study subjects based on the type of tympanoplasty, Type III tympanoplasty was most commonly performed in both the groups followed by type IV tympanoplasty. The study subjects have been followed up in the post-operative period according to the protocol as previously determined. Examination under microscope was carried out during each post-operative visit. The following parameters namely epithelialization of the mastoid cavity; presence of debris in the mastoid cavity; duration of otorrhoea; common postoperative complications like pain, vertigo, granulation tissue, morbidity of donor site etc; graft integrity noted at post-operative visits of 2 weeks, 4 weeks, 6 weeks and 12 weeks. The post-operative pure tone audiometry was performed at 12 weeks and the hearing outcome evaluated based on A-B gap closure.

Epithelialization of the mastoid cavity was noted as partial or complete during each of the post-operative visits. In group $A$, the mean duration required for complete epithelialization is 10.8 weeks with a standard deviation of 2.48 weeks. In group B, the average time taken for complete epithelialization is 5.07 weeks with a standard deviation of 2.12 weeks. The duration of epithelialization amongst the 2 groups have been assessed with unpaired t-test and it has been found that the duration of epithelialization is highly significant when group A (CWD Mastoidectomy without obliteration) is compared against group B

(CWD

Mastoidectomy with obliteration with cartilage).

As far as graft integrity is concerned, all cases had their graft intact at the end of 12 weeks. As far as post-operative pain was concerned, it was complained by 4 patients in the group without obliteration; 3 in case of obliteration with cartilage. There was no further complaint during the study period. Presence of debris in the mastoid cavity was then evaluated amongst the groups. Debris was present in group A for a mean duration of 9.47 weeks with a standard deviation of 3.25 weeks whereas in group B it seen for a mean duration of 2.8 weeks with a standard deviation of 1.26 weeks. Collection of debris in the mastoid cavity has been assessed using the same unpaired t-test as above with similar statistical significance being obtained between obliterated versus unobliterated group.

Vertigo in the post-operative period was complained mainly by patients in the group which did not undergo any obliteration procedures. 8 cases complained of vertigo in the immediate 2 nd week of post-operative visit, of which 5 cases had their symptoms resolved by the end of 4 weeks whereas another 2 individuals had persistent symptoms till the end of 6 weeks. By the end of 12 weeks no one complained of vertigo. In group B only 1 patient complained of vertigo at 2nd week which resolved subsequently with no such complaints during any of the subsequent post-operative visits.

Otorrhoea following canal wall down procedures being the most frequent complaint during the post-operative period has been evaluated next. Patients from group A complained of discharge from their ears for a mean duration of 7.47 weeks with a standard deviation of 2.88 weeks. Individuals of group $B$ have been found to have the duration of symptoms last an average of 2.8 weeks \pm 1.26 weeks. The duration of otorrhoea was evaluated using the same principles with no different statistical outcome, i.e., obliteration groups showing better results compared to group A.

At the end of 12 th post-operative week, all individuals were subjected to pure tone audiogram. In group A, the mean PTA was $36.06 \mathrm{~dB}$ with a standard deviation of $10.05 \mathrm{db}$. The mean A-B gap in group $A$ is $17.07 \mathrm{~dB}$ with a standard deviation of $10.59 \mathrm{db}$. In group $B$, the mean PTA was $34.13 \mathrm{~dB}$ with a standard deviation of $5.74 \mathrm{db}$. The mean A-B gap in group B is $14.13 \mathrm{~dB}$ with a standard deviation of $6.88 \mathrm{db}$. Each group showed statistically significant improvement in pre and post-operative pure tone audiometry and A-B gap when tested by paired $t$-test but the hearing gain in the individual groups when tested against each other failed to produce any statistical significance when tested by unpaired t-test. (Table 2)

\begin{tabular}{|ccc|}
\hline $\begin{array}{c}\text { Audiometric } \\
\text { Findings }\end{array}$ & $\begin{array}{c}\text { CWD without Obliteration (as } \\
\text { Control). }\end{array}$ & $\begin{array}{c}\text { CWD with Obliteration } \\
\text { with Cartilage }\end{array}$ \\
PTA & $39.06 \pm 10.05 \mathrm{~dB}$ & $34.13 \pm 5.74 \mathrm{~dB}$ \\
A-B gap & $17.07 \pm 10.59 \mathrm{~dB}$ & $14.13 \pm 6.88 \mathrm{~dB}$ \\
\hline \multicolumn{3}{|c|}{ Table 2. Distribution of Study Population Based on } \\
& Post-Operative Pure Tone Audiometry \\
\hline
\end{tabular}

\section{DISCUSSION}

The global burden of illness from CSOM involves 65-330 million individuals with draining ears, $60 \%$ of whom $(39-200$ 
million) suffer from significant hearing impairment. Over $90 \%$ of the burden is borne by countries in the South-east Asia and Western Pacific regions, Africa, and several ethnic minorities in the Pacific Rim. CSOM is uncommon in the Americas, Europe, the Middle East, and Australia. Among the South-East Asian countries, prevalence rate of CSOM in Thailand ranged from 0.9 to $4.7 \%$ while the Indian prevalence is $7.8 \% .^{10}$

The primary goal of middle ear surgery, whether or not the patient has a cholesteatoma, is extirpation of the disease, anatomical preservation of the middle ear, and functional restoration. ${ }^{11}$ The type of mastoidectomy is based on the extent of the disease, preoperative health of the patient, the status of the opposite ear, and both the surgeon's and patient's preference. ${ }^{10}$

The canal wall up mastoidectomy involves removing the mastoid air cells lateral to the facial nerve and otic capsule bone while preserving the posterior and superior external auditory canal walls. It preserves the normal anatomy of the ear canal, thus avoiding the risk of bowl problems and the necessity for periodic cleaning and leading to reduced healing time and, possibly, better hearing results. However, a high residual and recurrence rate continue to be major drawbacks to canal wall up surgery. ${ }^{10}$

The canal wall down technique creates an open cavity after removal of the bony posterior canal wall, providing excellent exposure for cholesteatoma removal. Recurrence rate is lowered up to $5-10 \%$. The main disadvantages of technique are related to the necessity for periodic cleaning of the mastoid cavity with persistent otorrhea. Other problems with open cavity include difficulty with the use of a hearing aid, water intolerance due to susceptibility to infection, and propensity to vertigo by a caloric stimulus such as warm/cold air or water. The risks for canal wall down mastoidectomy are reversed - lower risk of recurrence (2-10\%) but higher risk of otorrhoea (20-60\%). These problems can be minimized by different obliterative procedures. ${ }^{10}$

The concept of mastoid cavity obliteration was first introduced by Mosher in 1911. Mastoid reconstruction and obliteration procedures can be classified into two main categories: (a) Free grafts, which are further sub-divided to biologic and non-biologic and (b) local flaps.

With the advent of numerous techniques for mastoid obliteration, the debate continues till date regarding the best material that can be used for obliteration. Each method has some distinct benefits over the others. Although these techniques offer the major advantage of eliminating the cavity problem, there can be long-term problems. For example, some of the obliterated tissues can shrink over time, minimizing the effectiveness of the mastoid obliteration. ${ }^{11}$

Autologous cartilage has been reported to be a superior material compared with other materials not only because it is cost-effective and easily harvested and manipulated but also because its use can avoid the risk of acquired immunodeficiency syndrome, hepatitis or other body fluid transmissible diseases. ${ }^{12}$

The mean age of the individuals in Present study- in group A is 25.47 years with a standard deviation of 8.89 years; in group B is 26.33 years with a standard deviation of 11.73 years. The mean age of individuals in the study by Bhandary S et al. is $26.95+9.525$ years which is coinciding with Present study. ${ }^{13}$
In examination under the microscope, $62 \%$ subjects in Present study had cholesteatoma (comprising both PSRP with cholesteatoma as well as attic cholesteatoma group), nearly 9\% had granulation and 29\% comprised the remainder. In the study by Shraddha Deshmukh et al, $80 \%$ of patients had cholesteatoma, $13.3 \%$ had granulations and $6.6 \%$ comprised the remainder. ${ }^{14}$ The findings of Present study are in tune to the above study where individuals with cholesteatoma formed the majority followed by granulation tissue.

In the Present study nearly $89 \%$ individuals had mildmoderate degree of hearing loss. This finding is slightly different from that of the study by Shraddha Desmukh et al., where $33.3 \%$ had hearing loss of $<30 \mathrm{~dB}, 50 \%$ had hearing loss between 30 and $60 \mathrm{~dB}$ and only $16.6 \%$ had hearing loss $>60 \mathrm{db}^{14}$ We can see that the mean time required for complete epithelialization of un-obliterated mastoid cavities is around 3-6 months which correlates well with the study by Shraddha Desmukh et al where $94 \%$ cases showed epithelialization at the end of 6 months. ${ }^{14}$

The mean duration for complete epithelialization of cavities obliterated by cartilage is around 6-8 weeks which correlates well with the studies by Haeng Jae Kim et al. ${ }^{15}$ and A. Maniu et al. ${ }^{16}$ (Table 3 )

\begin{tabular}{|cc|}
\hline Study & Time \\
CWD without obliteration (as control) \\
Shraddha Deshmukh et al. & $94 \%$ at the end of 6 months \\
Present study & $10.8 \pm 2.48$ weeks \\
CWD with obliteration with cartilage \\
Shraddha Deshmukh et al. & $80 \%$ at the end of 6 months \\
Haeng Jae Kim et al. & $76 \pm 20$ days \\
A. Maniu et al. & 2 months \\
Present study & $5.6 \pm 2.03$ weeks \\
\hline Table 3. Time Required for Epithelialization
\end{tabular}

The time required to obtain a dry cavity was then compared. We can see that the time required to achieve a dry ear in un-obliterated cavities is around 8-10 weeks as seen in Present study which correlates well with the studies by Shraddha Desmukh et al. ${ }^{14}$

Cavities obliterated with cartilage achieved dry ear within 8 weeks as seen in various studies (Shraddha Deshmukh et $\mathrm{al}^{14} \mathrm{~S}$. Chhapola et $\mathrm{al}^{17}$ ). This correlates well with Present study where $2.8 \pm 1.26$ weeks was required to obtain a dry cavity. Post-operative vertigo was found to be significantly higher in groups that did not undergo any obliteration compared to groups that were obliterated with adipose.

Post-operative hearing has been found to improve in both the study groups. However, studies where no obliteration has been done, only a modest improvement in post-operative hearing is seen. ${ }^{11}$

\section{CONCLUSIONS}

Reviewing various literatures available on the subject of Canal Wall down Mastoidectomy, cavity problems, and techniques to obliterate the mastoid cavity, it has been seen that obliteration of the mastoid cavity offers possible solution to avoid the various cavity problems associated with a large mastoid cavity. However, no single obliterating material 
proved to be superior in comparison to other. This study, conducted to evaluate the outcomes of mastoid cavity obliteration and compare the outcomes of obliteration using autologous adipose has led to the following conclusions:

- healing of mastoid cavity in terms of epithelialization is significantly earlier in obliterated cavities.

- duration of otorrhoea in obliterated groups persisted for shorter intervals.

- collection of debris in cavity persisted for shorter intervals in obliterated cavities.

- hearing gain showed no difference when compared amongst the two groups though each group showed significant statistical improvement post-operatively.

Thus, it can be seen that cavity obliteration offers a simple solution to avoid cavity problems and also promotes early healing of mastoid cavity. Cartilage being easily available, it could be used for obliteration with ease. However, larger studies are needed to conclusively prove or refute the hypothesis statistically.

Authors thank the Principal and Medical Superintendent cum Vice Principal, Midnapore Medical College, Midnapore, for their kind permission to use the resources for the purpose of this publication. Also, contribution from all the faculty members and the residents of the department cannot be overlooked.

\section{Ethical Standards}

The permission from the IEC was obtained regarding the study and use of hospital data maintaining the privacy of the patients.

\section{REFERENCES}

[1] Gopen Q. Pathology and clinical course of the inflammatory diseases of the middle ear. In: Gulya AJ, Minor LB, Poe DS, eds. Glasscock-Schambaugh surgery of the ear. $6^{\text {th }}$ edn. Shelton, Connecticut: People's Medical Publishing House-USA 2010.

[2] Nadol JB. The chronic draining ear. In: Gates GA, ed. Current therapy in otolaryngology: head neck surgery. B.C. Decker Inc 1987:18-22.

[3] Browning GG. Merchant SN, Kelly G, et al. Chronic otitis media. In: Gleeson $M$, ed. Scott-Brown's otorhinolaryngology: head and neck surgery. $7^{\text {th }}$ edn. Great Britain: Edward Arnold Publishers Ltd 2008.

[4] Haynes DS, Wittkopf J. Canal-wall-up mastoidectomy. In: Gulya AJ, Minor LB, Poe DS, eds. Glasscock-Schambaugh surgery of the ear. $6^{\text {th }}$ edn. Shelton, Connecticut: People's Medical Publishing House-USA 2010.

[5] Kveton JF. Open cavity mastoid operations. In: Gulya AJ, Minor LB, Poe DS, eds. Glasscock-Schambaugh surgery of the ear. 6th ed. Shelton, Connecticut: People's Medical Publishing House-USA 2010.

[6] Rao US. Obliteration of mastoid cavity and reconstruction of attic area using conchal cartilage. Asian Pac J Health Sci 2016;3(1):140-3.

[7] Cho SW, Cho YB, Cho HH. Mastoid obliteration with silicone blocks after canal wall down mastoidectomy. Clin Exp Otorhinolaryngol 2012;5(1):23-7.

[8] Uçar C. Canal wall reconstruction and mastoid obliteration with composite multifractured osteoperiosteal flap. Eur Arch Otorhinolaryngol 2006;263(12):1082-6.

[9] Alves RD, Cabral Junior F, de Fonseca ACO, et al. Mastoid obliteration with autologous bone in mastoidectomy canal wall down surgery: a literature overview. Int Arch Otorhinolaryngol 2016;20(1):76-83.

[10] Singh M, Jain S, Rajput R, et al. Retrospective and prospective study of Singapore swing method on healing of mastoid cavity. Indian J Otolaryngol Head Neck Surg 2010;62(4):365-71.

[11] Lee HJ, Chao JR, Yeon YK, et al. Canal reconstruction and mastoid obliteration using floating cartilages and musculoperiosteal flaps. Laryngoscope 2017;127(5):1153-60.

[12] Kuo CL, Lien CF, Shio AS. Mastoid obliteration for pediatric suppurative cholesteatoma: long-term safety and sustained effectiveness after 30 years' experience with cartilage obliteration. Audiol Neurootol 2014;19(6):358-69.

[13] Bhandary S, Paudel D, Chettri ST, et al. Obliteration of mastoid cavity with temporalis muscle pedicle and abdominal fat graft and compare the efficacy of each method: a prospective randomized clinical trial. Otolaryngology Online Journal 2015;5(3).

[14] Deshmukh S, Sharma A, Dabholkar J. Mastoid cavity obliteration: our experience. Otolaryngol Pol 2012;66(6):379-81.

[15] Kim HJ, Shin MS, Cho YB, et al. The effect of mastoid obliteration technique using superiorly based musculoperiosteal flap and autologous conchal cartilage. Korean J Otolaryngol-Head Neck Surg 2001;44(12):1264-9.

[16] Maniu A, Cosgarea M. Mastoid obliteration with concha cartilage graft and temporal muscle fascia. ORL J Otorhinolaryngol Relat Spec 2012;74(3):141-5.

[17] Chhapola S, Matta I. Mastoid obliteration versus open cavity: a comparative study. Indian J Otolaryngol Head Neck Surg 2014;66(Suppl 1):207-13. 